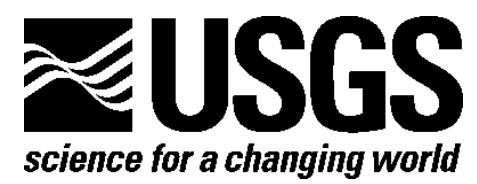

Prepared in cooperation with the U.S. Environmental Protection Agency

\title{
An Evaluation of Remote Sensing Technologies for the Detection of Fugitive Contamination at Selected Superfund Hazardous Waste Sites in Pennsylvania
}

By E.Terrence Slonecker and Gary B. Fisher

Open-File Report 2014-1081

U.S. Department of the Interior

U.S. Geological Survey 


\section{U.S. Department of the Interior Sally Jewell, Secretary}

\section{U.S. Geological Survey Suzette M. Kimball, Acting Director}

U.S. Geological Survey, Reston, Virginia: 2014

For more information on the USGS—-the Federal source for science about the Earth, its natural and living resources, natural hazards, and the environment-visit http://www.usgs.gov or call 1-888-ASK-USGS

For an overview of USGS information products, including maps, imagery, and publications, visit $h t t p: / / w w w . u s g s . g o v / p u b p r o d$

To order this and other USGS information products, visit http://store.usgs.gov

Suggested citation:

Slonecker, E.T., and Fisher, G.B., 2014, An evaluation of remote sensing technologies for the detection of fugitive contamination at selected Superfund hazardous waste sites in Pennsylvania: U.S. Geological Survey Open-File Report 2014-1081, 23 p., http://dx.doi.org/10.3133/ofr20141081/.

Any use of trade, firm, or product names is for descriptive purposes only and does not imply endorsement by the U.S. Government.

Although this information product, for the most part, is in the public domain, it also may contain copyrighted materials as noted in the text. Permission to reproduce copyrighted items must be secured from the copyright owner.

ISSN 2331-1258 


\section{Contents}

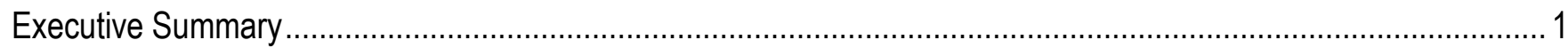

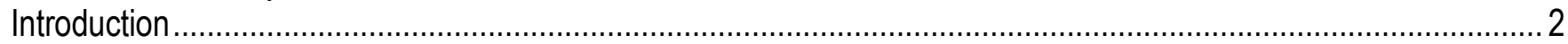

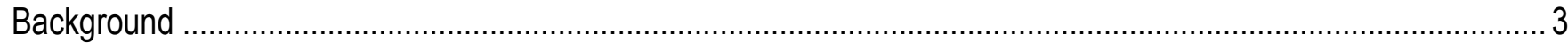

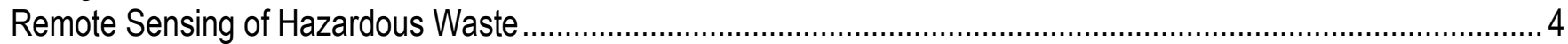

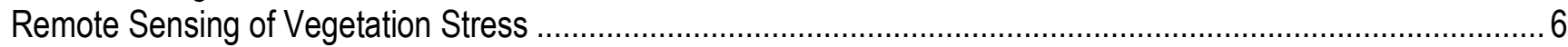

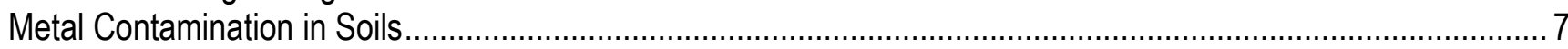

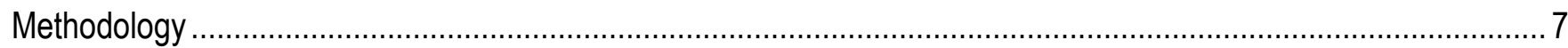

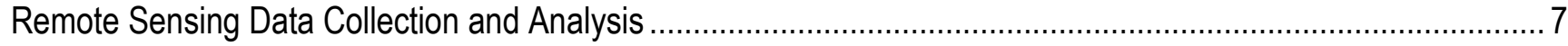

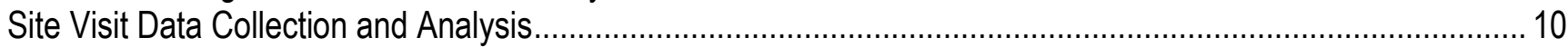

Analysis and Quality Control ............................................................................................................... 11

Criteria for Elevated Metal Concentrations............................................................................................. 11

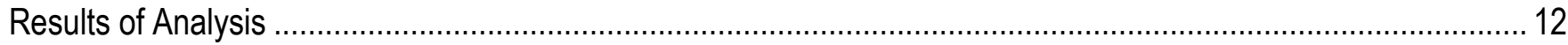

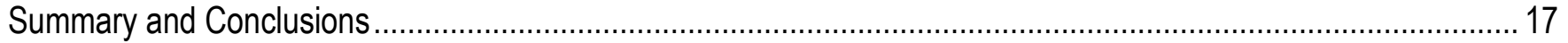

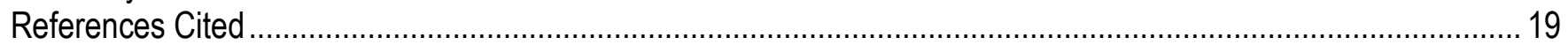

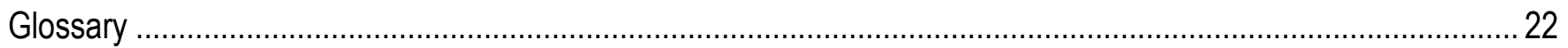

\section{Figures}

1. Map showing the locations of the 16 deleted Superfund test sites in Pennsylvania .................................... 3

2. Hyperspectral images are collections of hundreds of bands of coregistered imagery ................................5

3. When processed, the image cube can be analyzed with conventional spectroscopic analysis methodshence, the term "imaging spectroscopy" ........................................................................................

4. Photographs showing the combined hyperspectral techniques used in this report.................................... 9

5. The solar-reflected electromagnetic spectrum coverage of the Civil Air Patrol's Airborne Real-Time Cueing Hyperspectral Enhanced Reconnaissance system and Analytical Spectral Devices instruments ..... 9

6. Photograph showing soil sampling and field $X$-ray fluorescence screening ........................................... 10

7. Photograph showing Office of the Inspector General evaluators standing next to a large debris pile during a site visit to Taylor Borough Dump

8. A, Hyperspectral image analysis of vegetation and debris stress and $B$, ground photo of large trash pile at Taylor Borough Dump .................................................................................................... 15

9. Bruin Lagoon: $A$, Panchromatic image on left and $B$, hyperspectral anomaly detection image on right. .....16

10. Continuum-removed plot of normal vegetation and a vegetation anomaly, showing loss of photosynthetic band depth around 680 nanometers and a general "red-edge" shift of 8-12 nm, consistent with previously published results on natural gas stress

\section{Tables}

1. The deleted Superfund (SF) sites in an evaluation of remote sensing technologies for the detection of fugitive contamination at selected SF hazardous waste sites in Pennsylvania.

2. Listing for the background, residential-, and industrial risk-based concentrations (RBC) of selected metals.

3. A summary of the results of the detection of fugitive contamination at selected Superfund hazardous waste sites in Pennsylvania. 


\section{Conversion Factors}

\begin{tabular}{|c|c|c|}
\hline Multiply & By & To obtain \\
\hline \multicolumn{3}{|c|}{ Length } \\
\hline inch (in.) & 2.54 & centimeter $(\mathrm{cm})$ \\
\hline foot $(\mathrm{ft})$ & 0.3048 & meter (m) \\
\hline mile (mi) & 1.609 & kilometer $(\mathrm{km})$ \\
\hline \multicolumn{3}{|c|}{ Area } \\
\hline acre & 4,047 & square meter $\left(\mathrm{m}^{2}\right)$ \\
\hline acre & 0.4047 & hectare (ha) \\
\hline
\end{tabular}

\section{Abbreviations}

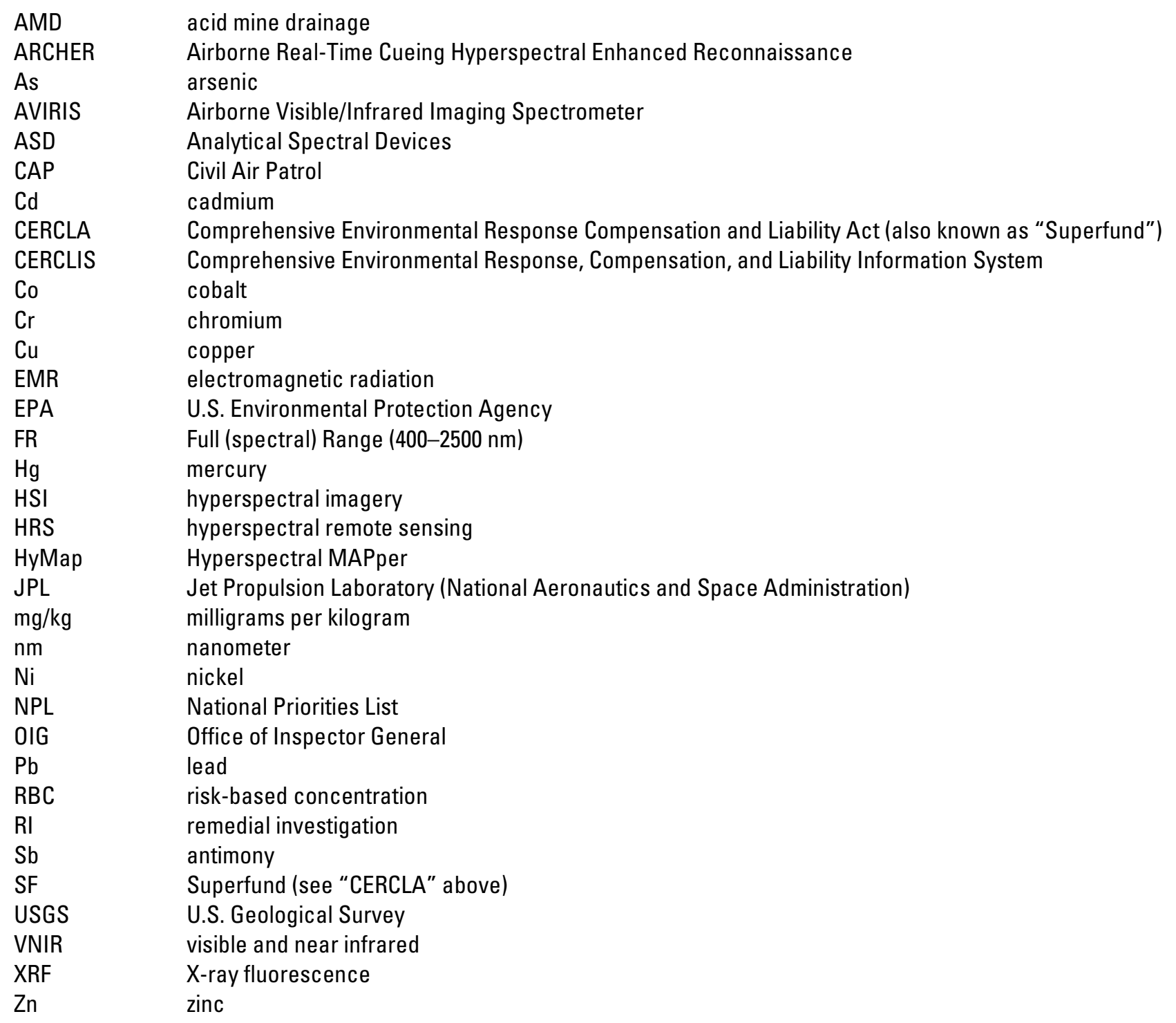




\title{
An Evaluation of Remote Sensing Technologies for the Detection of Fugitive Contamination at Selected Superfund Hazardous Waste Sites in Pennsylvania
}

\author{
By E. Terrence Slonecker and Gary B. Fisher
}

\section{Executive Summary}

This evaluation was conducted to assess the potential for using both traditional remote sensing, such as aerial imagery, and emerging remote sensing technology, such as hyperspectral imaging, as tools for postclosure monitoring of selected hazardous waste sites. Sixteen deleted Superfund (SF) National Priorities List (NPL) sites in Pennsylvania were imaged with a Civil Air Patrol (CAP) Airborne Real-Time Cueing Hyperspectral Enhanced Reconnaissance (ARCHER) sensor between 2009 and 2012. Deleted sites are those sites that have been remediated and removed from the NPL. The imagery was processed to radiance and atmospherically corrected to relative reflectance with standard software routines using the Environment for Visualizing Imagery (ENVI, ITT-VIS, Boulder, Colorado) software. Standard routines for anomaly detection, endmember collection, vegetation stress, and spectral analysis were applied.

Onsite visits and field work were conducted at 12 of the 16 sites. Field work consisted of the collection of soil samples; a general inspection of site conditions; the collection of sediment and water samples where conditions indicated possible contaminants; and informal interviews with local officials, residents, and property owners. Laboratory analysis consisted of hyperspectral data collection and analysis, spectral image-processing techniques, and X-ray fluorescence (XRF) analysis of soil and sediments for metals. At four sites, access could not be obtained in a timely manner or other technical issues precluded site visits. Each of the remaining 12 sites was analyzed for land use setting, physical security, imagery anomalies, points of interest, and spectral identifications. Soil sampling was conducted at each site with a XRF analyzer, and soil samples were collected for confirmation and additional analysis in the laboratory using an Analytical Spectral Devices (ASD) Full Range (FR) spectroradiometer (Analytical Spectral Devices Inc., Boulder, Colorado).

Remote sensing and field visits indicated that there were operations and maintenance issues at four sites: Aladdin Plating, Hranica Landfill, Publicker Industries, and Taylor Borough Dump. These issues consisted of discarded equipment and general industrial debris. At Taylor Borough, there were large mounds of debris and general waste material. At the Hranica Landfill, there was a discharge of rust-colored leachate.

In general, 9 of the 12 sites visited were relatively clean and without any detectable matters of concern regarding operations and maintenance, vegetation stress, or soil contamination. There were potential contamination concerns detected by hyperspectral analysis at Bruin Lagoon, Hranica Landfill, and Taylor Borough Dump. Bruin Lagoon displayed still unexplained vegetation anomalies; Hranica Landfill and Taylor Borough both contained considerable levels of trash and debris. Although the ability to monitor and detect potential problems at deleted SF sites was the objective of the study, the relatively 
"clean" condition of most of the sites did not result in a thorough evaluation of remote sensing technology under a variety of site conditions. Research on the remote sensing of contaminants relies on the existence of those contaminants on or near the surface. Future remote sensing research should consider utilizing areas of known contamnination.

\section{Introduction}

This report describes a remote sensing research effort conducted by the U.S. Geological Survey (USGS), in cooperation with the U.S. Environmental Protection Agency (EPA), Office of Inspector General (OIG). The objective of the research was to explore the capability of remote sensing as a technology for the OIG to use in planning and conducting evaluations of the adequacy of the EPA's postclosure monitoring of hazardous waste sites as defined under the Comprehensive Environmental Response Compensation and Liability Act, also known as "Superfund" (SF), and to evaluate possible contamination at specific sites.

Sixteen deleted SF sites in Pennsylvania were imaged with a hyperspectral sensor from September 2009 to April 2012. Twelve of the 16 sites were subsequently visited for inspection of general site conditions and for the collection of soil and water samples and spectral measurements with field-portable spectrometers. Figure 1 shows the geographic locations of the 16 sites.

The 16 deleted SF sites are listed in table 1 below:

Table 1. The deleted Superfund (SF) sites in an evaluation of remote sensing technologies for the detection of fugitive contamination at selected SF hazardous waste sites in Pennsylvania.

\begin{tabular}{|c|c|c|}
\hline Name & CERCLIS ID & Municipality or Township \\
\hline 1. Aladdin Plating & PAD075993378 & Clarks Summit. \\
\hline 2. Berkley Products Dump & PAD980538649 & Denver. \\
\hline 3. Berks Landfill & PAD000651810 & Sinking Spring. \\
\hline 4. Brodhead Creek & PAD980691760 & Stroudsburg. \\
\hline 5. Bruin Lagoon & PAD980712855 & Bruin. \\
\hline 6. Helbelka Auto Salvage ${ }^{1}$ & PAD980829329 & Upper Macungie Township. \\
\hline 7. Hranica Landfill & PAD980508618 & Buffalo Township. \\
\hline 8. Lackawanna Refuse & PAD980508667 & Old Forge. \\
\hline 9. Lansdowne Radiation ${ }^{1}$ & PAD980830921 & East Lansdowne. \\
\hline 10. McAdoo - Blaine & PAD980712616 & McAdoo. \\
\hline 11. McAdoo - Kline & PAD980712616 & McAdoo. \\
\hline 12. Metropolitan Mirror ${ }^{1}$ & PAD982366957 & Frackville. \\
\hline 13. Publicker Industries & PAD981939200 & Philadelphia. \\
\hline 14. Taylor Burrough Dump & PAD980693907 & Taylor. \\
\hline 15. Voortman Farms ${ }^{1}$ & PAD980692719 & Ladark. \\
\hline 16. Wade ABM & PAD980539407 & Chester. \\
\hline
\end{tabular}

\footnotetext{
${ }^{1}$ Sites not visited during field work.
} 
Field work was undertaken at 12 sites. Technical failure of the remote sensing system occurred at one site (Voortman Farms), and timely access could not be obtained at three others (Helbelka Auto Salvage, Landsdowne Radiation, and Metropolitan Mirror). This research seeks to evaluate traditional and hyperspectral imagery (HSI) and field spectroscopic measurement techniques in the characterization and analysis of fugitive (anthropogenic and uncontrolled) contamination at previously remediated hazardous waste disposal sites.

\section{Background}

In 2007, the EPA OIG-issued Evaluation Report 2007-P-00039—“ ' Limited Investigation Led to Missed Contamination at Ringwood Superfund Site" (U.S. Environmental Protection Agency, 2007), which documented problems of insufficient characterization and cleanup at the Ringwood, New Jersey, National Priority List (NPL) SF Site.

\section{Pennsylvania Deleted EPA Superfund Sites}

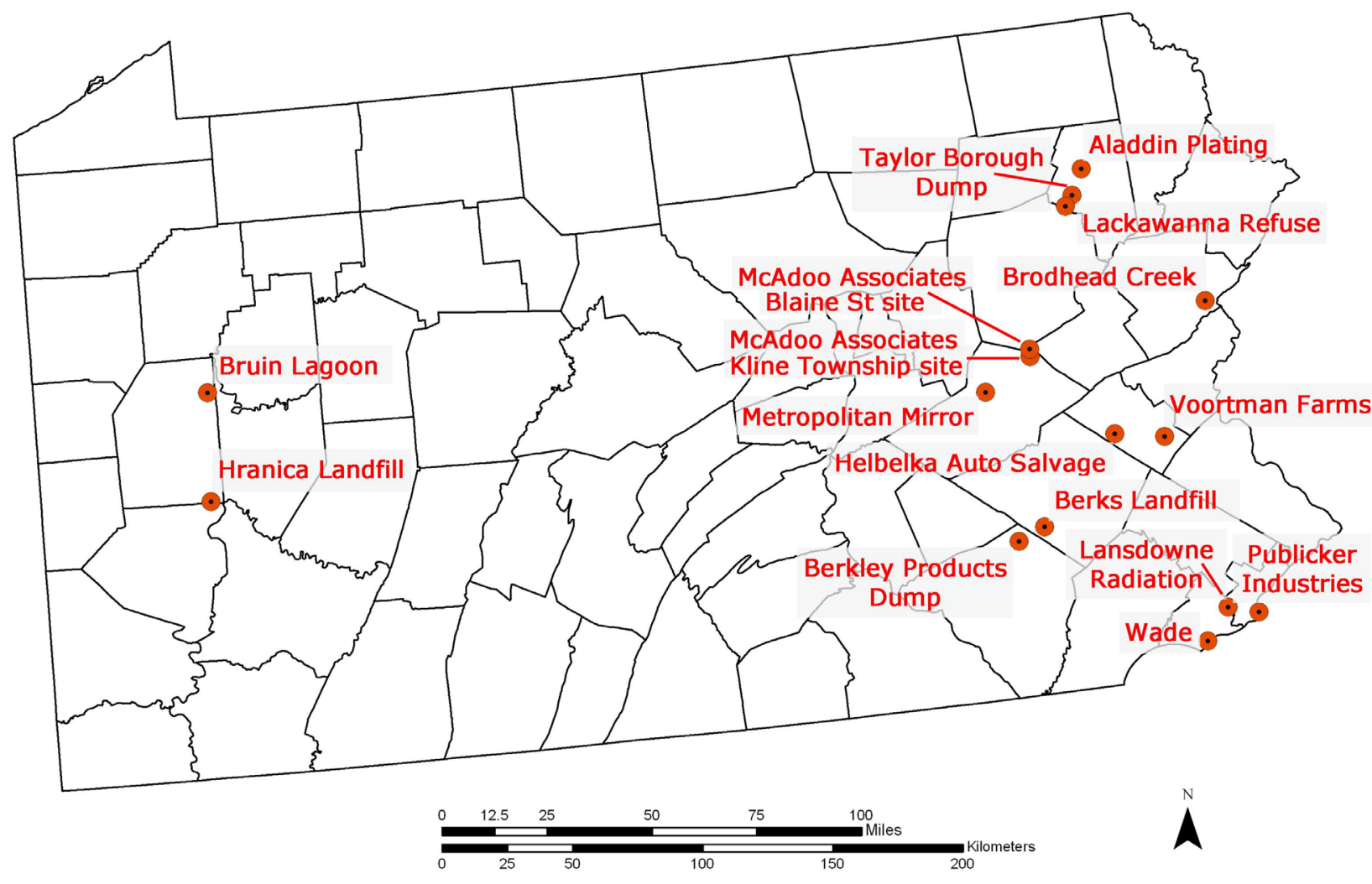

Figure 1. Locations of the 16 deleted Superfund test sites in Pennsylvania.

A key finding of the OIG report was that the failure to detect the extent of contamination at the Ringwood Site might have been avoided if the EPA had made greater use of available aerial 
photographs. Morphological characteristics of the landscape and landscape changes, as documented in historical aerial imagery, could have been used to detect the much larger extent of paint sludge and contamination than was thought to exist after the initial remedial investigation (RI) (Baker, 1984; U.S. Environmental Protection Agency, 2007). Based on the findings from the Ringwood investigation, the OIG asked the USGS to evaluate the potential use of current and emerging remote sensing technology in the investigations of deleted SF sites.

This research, summarized in USGS Open-File Report 2011-1050 (Slonecker and Fisher, 2011) found that two of five sites evaluated had detectable postclosure issues with site activity, soil metals, and onsite debris, most of which were identified by remote sensing in some form. This research is a follow-on effort for the deleted SF sites in Pennsylvania.

\section{Remote Sensing of Hazardous Waste}

Remote sensing is an increasingly important science for advancing understanding of environmental processes, conditions, and changes affecting both human and ecological health. Advancements in sensor technology and processing algorithms have resulted in technical capabilities that can record and identify earth surface materials, including waste products, based on the interaction of electromagnetic energy with the molecular structure of the material being sensed (Goetz and others, 1985; Green and others, 1998; Clark 1999; Clark and others, 2009). Hyperspectral remote sensing (HRS) records reflected and emitted electromagnetic energy in hundreds of narrow wavelengths, which result in data that can be analyzed with the same chemical spectroscopic techniques that have been used by chemists and astronomers for over a century. Spectral reflectance of vegetation and other landscape conditions have received renewed interest by the remote sensing community during the past decade because of the development of this new class of imaging technology. Many of the early and definitive studies in spectral reflectance utilized spectroscopic measurement instruments in a laboratory setting (Horler and others, 1980; Chang and Collins, 1983; Milton and others, 1989). These instruments measured reflected energy and produced spectra that could be analyzed using standard spectral analysis techniques. The collection of hyperspectral imagery (HSI) in very narrow bandwidths across the solarreflected part of the electromagnetic spectrum [from 400 to 2,500 nanometers (nm)] results in a digital file of hundreds of bands of coregistered imagery, sometimes called an "image cube" (see fig. 2). After processing, the image cube represents an imagery version of the same energy and matter interactions measured in the laboratory, and can be analyzed with a variety of standard and emerging statistical methods in spectroscopy, signal processing, and remote sensing. Reflectance spectra can be used to identify certain compounds, materials, and their conditions based on the interaction of photons of light with the molecular structure of the target material (Vane and Goetz, 1988; Green and others, 1998; Clark 1999) (see fig. 3).

Spectroscopic analysis techniques can now be employed outside of the laboratory through the use of HRS-imaging techniques and portable field spectroradiometers. In addition, new analytical techniques are being developed and refined that permit the identification and analysis of key environmental processes, such as photosynthesis and nutrient cycling, which are important for the detection of anthropogenic stress that might be caused by soil or groundwater contamination. 


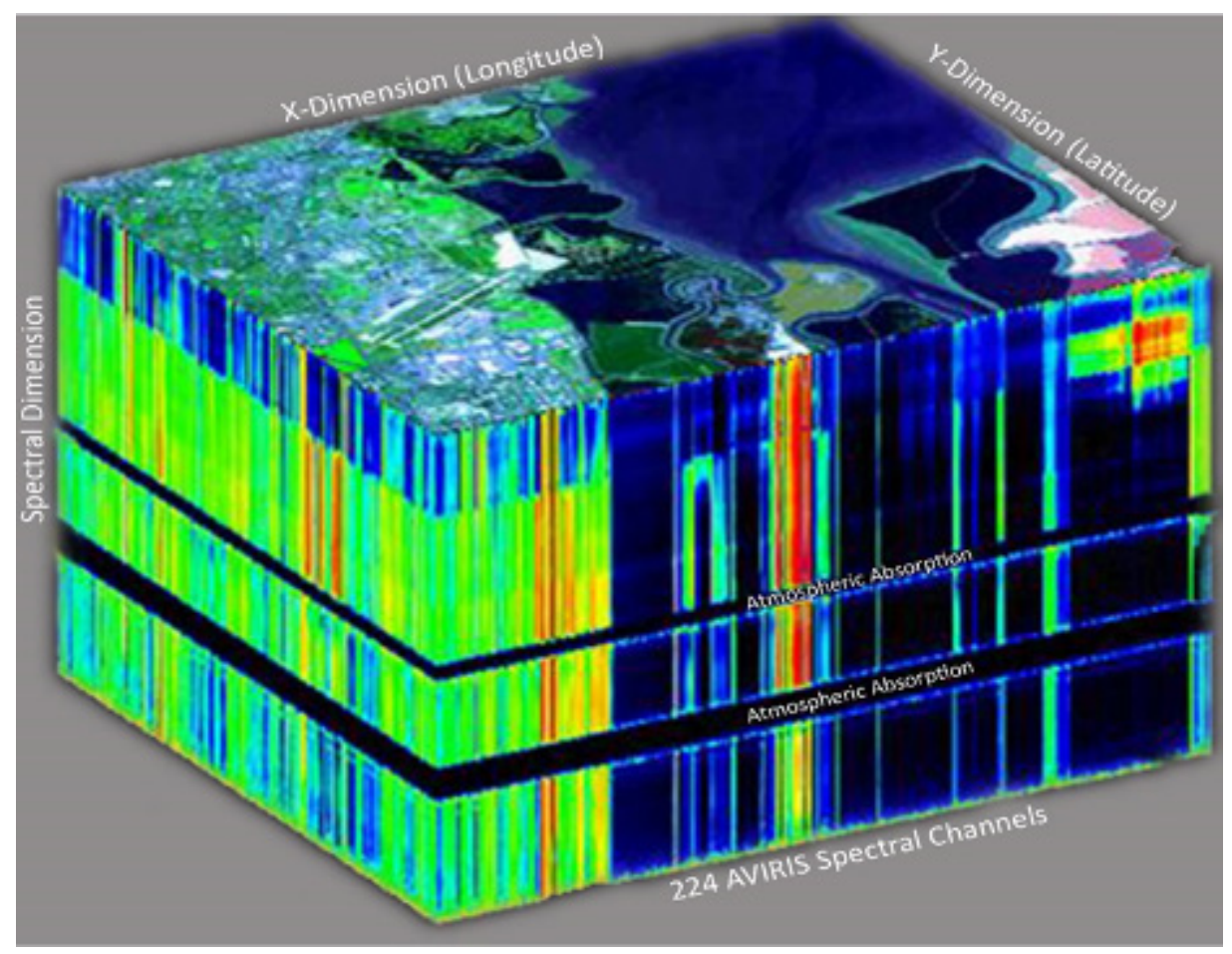

Figure 2. Hyperspectral images are collections of hundreds of bands of coregistered imagery. Each band collects reflected energy in a slightly different wavelength location and results in what is often called an "image cube." The image shown here, of Moffett Field, California, was collected on August 20, 1992, from a height of 20,000 meters. [Image from the Jet Propulsion Laboratory-Airborne Visible/Infrared Imaging Spectrometer Web site http://aviris.jpl.nasa.gov/html/aviris.cube.html (National Aeronautics and Space Administration, 2010).

Although imaging spectroscopy of plant and tree health has been an important research area for some time, recent research suggests that there is a spectral distinction between natural stress, such as drought, and anthropogenic stress, such as soil chemical contamination, due to different physiological responses of the plant (Zinnert and others, 2012). Further development of this capability would be an important aspect of hyperspectral research. 


\section{AVIRIS CONCEPT}

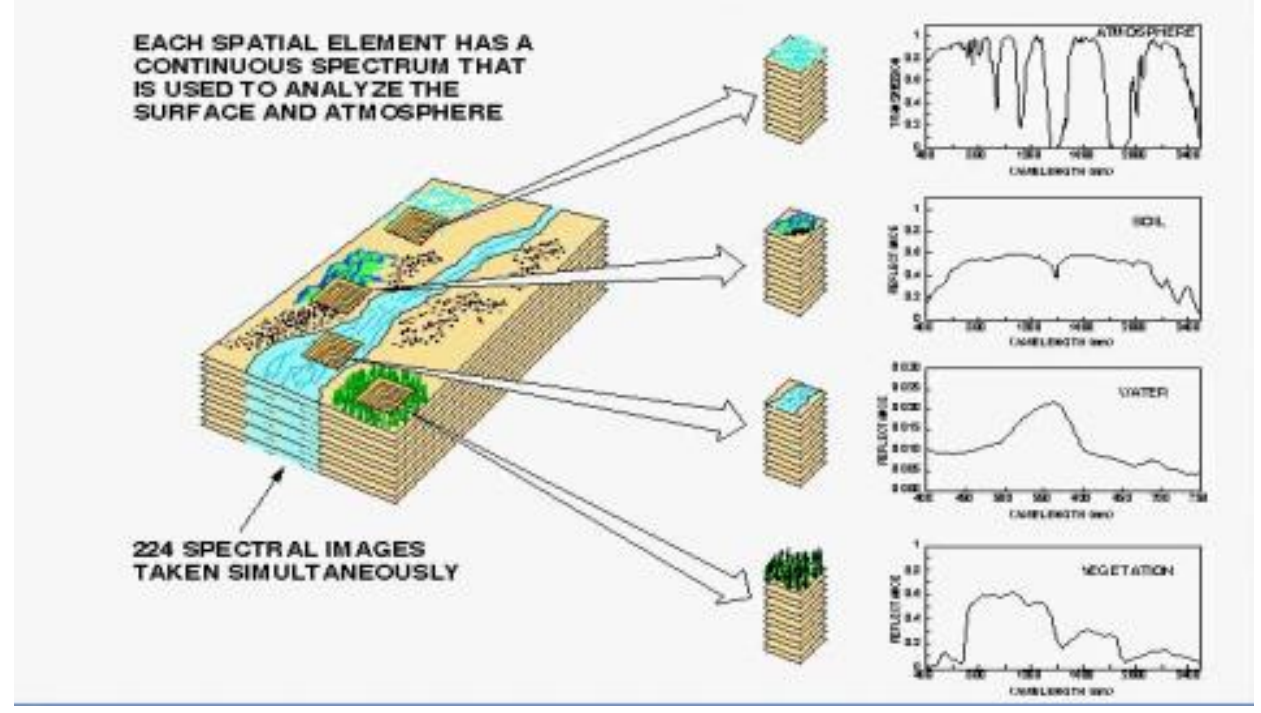

Figure 3. When processed, the image cube can be analyzed with conventional spectroscopic analysis methodshence, the term "imaging spectroscopy." [Image from the Jet Propulsion Laboratory-Airborne Visible/Infrared Imaging Spectrometer Web site (http://aviris.jpl.nasa.gov/html/aviris.concept.html)] (National Aeronautics and Space Administration, 2007).

\section{Remote Sensing of Vegetation Stress}

A key aspect in the study of fugitive hazardous waste in the environment is the effect that contaminants have on cover vegetation. In most cases, soil or groundwater contaminants, such as hydrocarbons, heavy metals, and organic chemicals, will have negative effects on the metabolism and growth of typical cover vegetation, such as trees or grasses. Remote sensing of vegetation stress has been, and continues to be, a key aspect of remote sensing research (Milton and others, 1989; Noomen and others, 2008; Zinnert and others, 2012).

As far back as 1879 , researchers, using crude spectrographs, were documenting the differences in vegetation reflectance in different broad bands of the visible spectrum (Rood, 1879; Willstatter and Stoll, 1913, 1918). Schull (1929) studied and measured the reflectance of various leaves using a prism spectrophotometer to attempt to better explain leaf-energy interactions that occur in photosynthesis. As aerial photography, film, and camera systems became available and more sophisticated, applications for crop monitoring became routine agricultural practice and included a seminal paper from Colwell (1956) for identifying crop diseases from aerial photography.

As both spectroscopic and remote sensing systems developed further, specific patterns of vegetation stress began to emerge and spawned a flurry of research starting in the 1990s. The shift in the "red edge" of vegetation reflectance $(680 \mathrm{~nm}$ to $730 \mathrm{~nm})$, related to plant health and (or) stress, was identified and utilized in a number of research studies and is still used today in studying vegetation condition. A series of special spectral calculations, called "vegetation indices," were developed to maximize and take advantage of high-spectral resolution and specific quality of vegetation growth and health (Thenkabail, 2000). They are derived from the spectral reflectance properties of vegetation and are designed to accentuate a specific property of vegetation, such as leaf moisture content. As hazardous waste sites that have been remediated and deleted on the SF NPL list are likely to have been reclaimed 
or revegetated, vegetation indices are a key component of assessing surface contamination of these sites (Slonecker and others, 2010).

\section{Metal Contamination in Soils}

One of the primary concerns for remote sensing analysis of deleted SF sites is metal contamination in the soil. Both the direct reflectance of metals in the soil matrix and the effect of metals on vegetation reflectance are potential observables in this environment. Many naturally occurring metals are constituents of minerals and of the surficial and crustal properties of soils. In mineral form, such as galena [lead $(\mathrm{Pb})]$ and sphalerite [zinc $(\mathrm{Zn})]$, metals occur naturally throughout the Earth's crust and can often be identified through field or imaging spectroscopy. However, when mined for the specific metal or used in industrial processes, waste metal concentrations in soils can be orders of magnitude higher than natural concentrations and become risks to human and ecological health.

The identification of metals and metal concentrations in soils generally involves wet chemical acid digestion and methods such as EPA Method 7421 for Pb and EPA Method 7060A for arsenic (As). In recent years, XRF methods (EPA Method 6200) have also become accepted field methods for the determination of metals in soils. Only XRF methods were used in this study.

All of the above-mentioned methods require the collection of samples and laboratory analysis or, in the case of XRF technology, physical contact with the soil. A remote sensing method that might identify soil contamination remotely could be a major new monitoring tool. Several studies have indicated the possibility of applying field and imaging spectroscopy in the identification of minerals containing heavy metals as an indicator of contamination in mining areas (Farrand and Harsanyi, 1997; Ferrier, 1999). Montero and others (2005) assessed the potential of abandoned mines for acid mine drainage (AMD) by characterizing waste rock associated with acid drainage.

Studies by Kemper and Sommer (2002) and Choe and others (2008) have demonstrated that direct, stand-off detection of high metal concentrations in soils is possible. Wu and others (2007) have shown that visible and near-infrared (VNIR) spectroscopy produced strong negative correlations with certain metals [As, cadmium $(\mathrm{Cd})$, chromium $(\mathrm{Cr})$, copper $(\mathrm{Cu})$, mercury $(\mathrm{Hg}), \mathrm{Pb}$, and $\mathrm{Zn}$ ] in contaminated soils, depending on iron oxide and organic carbon content.

Choe and others (2008) demonstrated that a band ratio of 610 nanometers $(\mathrm{nm}) / 500 \mathrm{~nm}$ and $1,344 \mathrm{~nm} / 778 \mathrm{~nm}$ correlated with concentration of $\mathrm{Pb}, \mathrm{Zn}$, and As in soils. Wu and others showed that continuum removed band depths at $610 \mathrm{~nm}$ and $830 \mathrm{~nm}$ were diagnostic for $\mathrm{Cr}$ and $\mathrm{Cu}$ in soil.

\section{Methodology}

\section{Remote Sensing Data Collection and Analysis}

Imagery was collected at sites defined by EPA. Sites were visited to collect additional spectra and soil samples as a ground truth for the remotely sensed data. Imagery and soils data were analyzed in the laboratory.

Remote sensing data were collected in two forms. First, hyperspectral data from the CAP's ARCHER system were collected for each site between September 2009 and April 2012. Collection dates and times were not always optimal due to a number of administrative, programmatic, and weatherrelated issues and delays. The ARCHER system represents a low-cost alternative for high-spatial and spectral-resolution remote sensing data. In addition, soil samples were screened in the laboratory with an ASD FR field spectrometer for potential hydrocarbon and organic signatures that have been demonstrated in the near-infrared region by King and Clark (1989), Allen and Krekeler (2010), Cloutis 
(1989), and Slonecker and others (2010). Figure 4 shows the different data collection strategies. Although the presence of hydrocarbons and other organics is unlikely under a postclosure site scenario, the combination of both ARCHER imagery and the ASD laboratory analysis represents a full analysis of potential signatures for hazardous waste that might exist in the solar-reflected portion of the electromagnetic spectrum from 400 to $2,500 \mathrm{~nm}$. Figure 5 shows the coverage of the two sensors in the electromagnetic spectrum.

ARCHER utilizes a grating spectrometer and includes 52 bands covering the $500-1,100-\mathrm{nm}$ spectral range. The system uses a special camera facing down through a quartz glass portal in the belly of the aircraft, which is typically flown at a standard mission altitude of 2,500 feet [800 meters (m)], $100 \mathrm{knots}(50 \mathrm{~m} / \mathrm{second})$ ground speed and a $1-\mathrm{m}$ spatial resolution, and a 500-m image swath width. The ARCHER system has a 36-degree field of view and a 100:1 signal-to-noise ratio. ARCHER technical details can be found in Stevenson and others (2005). ARCHER combines a VNIR hyperspectral imaging system, a high-resolution, visible panchromatic imaging sensor; and an integrated geopositioning and inertial navigation unit with onboard real-time processing for data acquisition and correction, precision image georegistration (Civil Air Patrol, 2009).
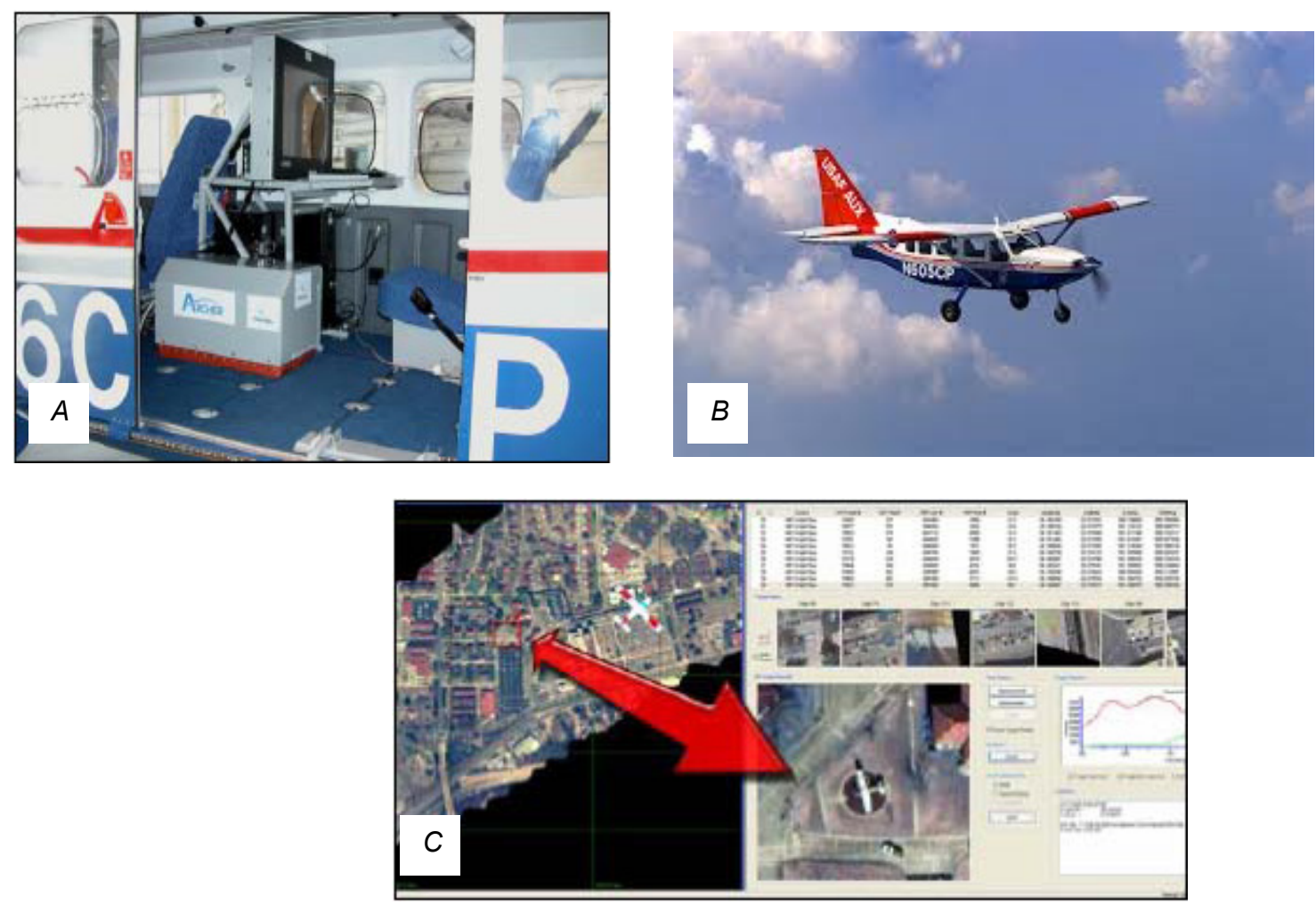

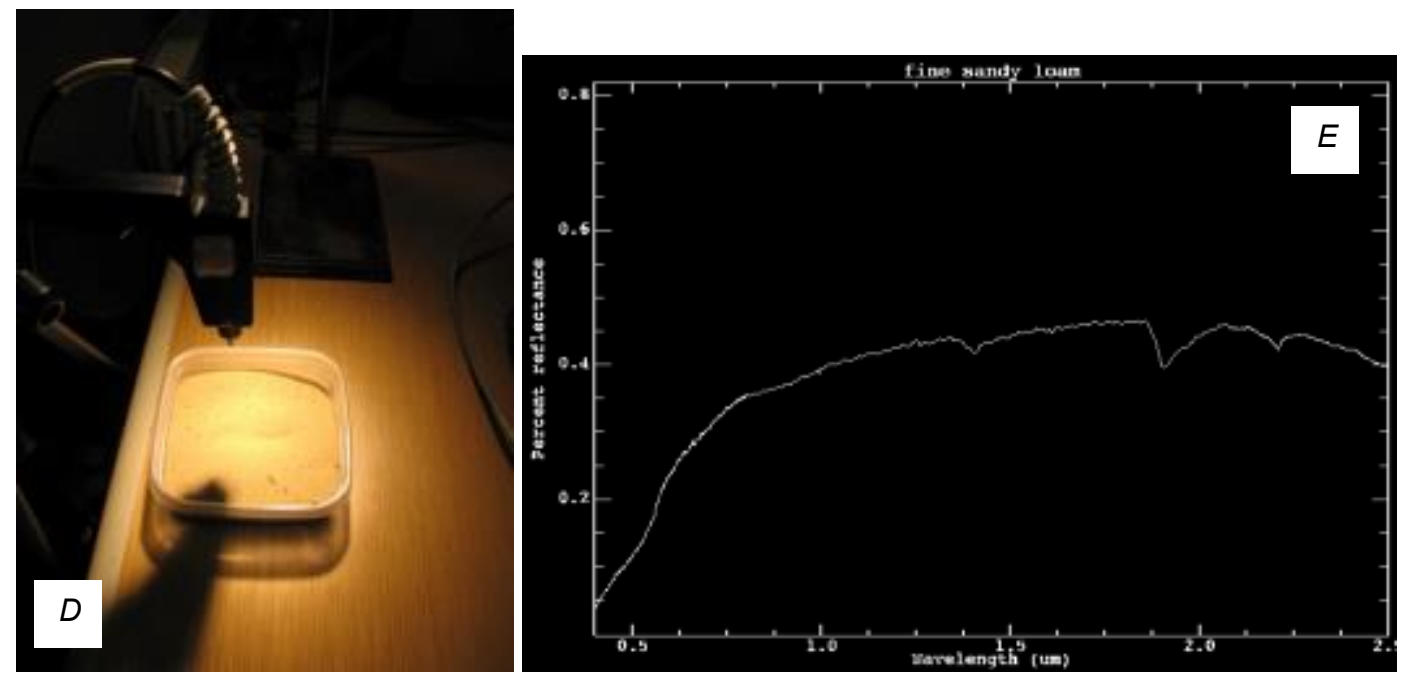

Figure 4. The combined hyperspectral techniques used in this report: $A$, the Civil Air Patrol's (CAP) Airborne Real-Time Cueing Hyperspectral Enhanced Reconnaissance (ARCHER) sensor; $B$, the CAP aircraft; $C$, imagery and spectra from the ARCHER sensor; $D$, full-range spectroscopy in the laboratory with the Analytical Spectral Devices (ASD) spectroradiometers; and $E$, an example spectra from the ASD system.

\section{SOLAR REFLECTED SPECTRUM}

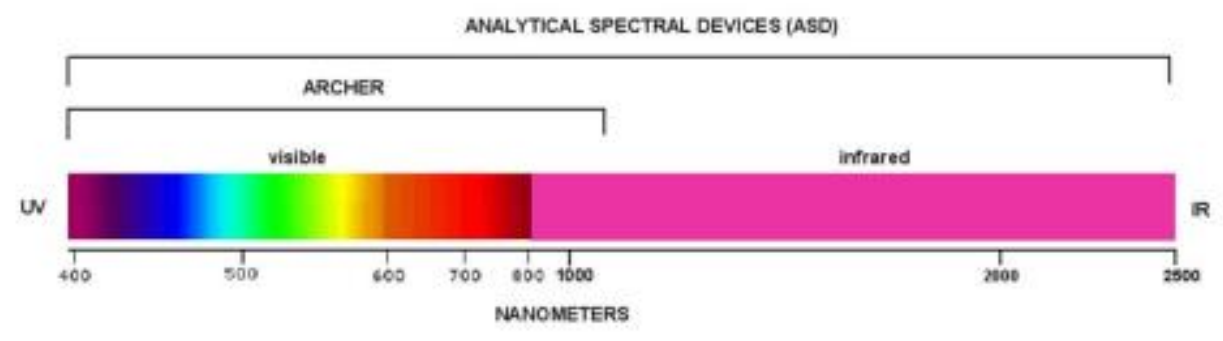

Figure 5. The solar-reflected electromagnetic spectrum coverage of the Civil Air Patrol's Airborne Real-Time Cueing Hyperspectral Enhanced Reconnaissance (ARCHER) system and Analytical Spectral Devices instruments (from Slonecker and Fisher, 2011).

XRF technology was used to measure the metal content of the soils at the field visit sites. XRF is an accepted method of soil elemental analysis by which X-ray-fluorescence emission of a material is measured after bombardment by high-energy gamma or X-rays (Thermo Scientific, 2013). Fieldportable units permit analysis of the metal content of soils in the field and can help identify areas where metals contamination is present (see fig. 6).

Hyperspectral imagery and analysis, often referred to as "imaging spectroscopy," is a meld of remote sensing and chemical analysis techniques that provide a powerful method for the identification of substances and conditions that maximize the informational content of VNIR spectroscopy, with the synoptic efficiency of overhead remote sensing. Many unique substances can be detected with imaging spectroscopy methods. One such example that is relevant to waste sites is that of hydrocarbons, such as waste oil that was detected previously. Hydrocarbons have distinctive absorption features at 1,200, 
1,731 , and 2,310 $\mathrm{nm}$, and they are a strong indicator of waste disposal activity. Another example of hyperspectral capabilities lies in the many vegetation indices that have been developed for specialized analysis. One such index is the photochemical reflectance index (PRI) that measures carotenoid pigments and thus, light use efficiency in plants, giving a measure of productivity and stress in the physiological status of the plant. PRI is computed from hyperspectral wavebands using the following formula:

$$
\mathrm{PRI}=\frac{\mathrm{W}_{531}-\mathrm{W}_{570}}{\mathrm{~W}_{531}+\mathrm{W}_{570}}
$$

where $\mathrm{W}_{531}$ and $\mathrm{W}_{570}$ are the values at specific wavelengths in the reflected spectrum. Developed by Gamon and others $(1992,1997)$, this formula has proven successful at identifying subtle patterns of stress that could be caused by soil contamination. Although PRI is commonly used in vegetation stress scenarios, there are many other indicies that have been calculated and used effectively (Thenkabail and others, 2000).

\section{Site Visit Data Collection and Analysis}

Field visits for site inspection and sample collection and analysis were conducted in 2012. Arrangements for site visits were coordinated through the EPA Regional Office and with the appropriate land owners and administrators. During visits, sites were reviewed for general conditions and visual appearance. Sampling was conducted using a grid pattern and at specific areas of interest based on the remote sensing analysis. Soil samples were screened and collected for metals analysis via portable XRF technology. Figure 6 shows the handheld XRF instrument being used in the field.

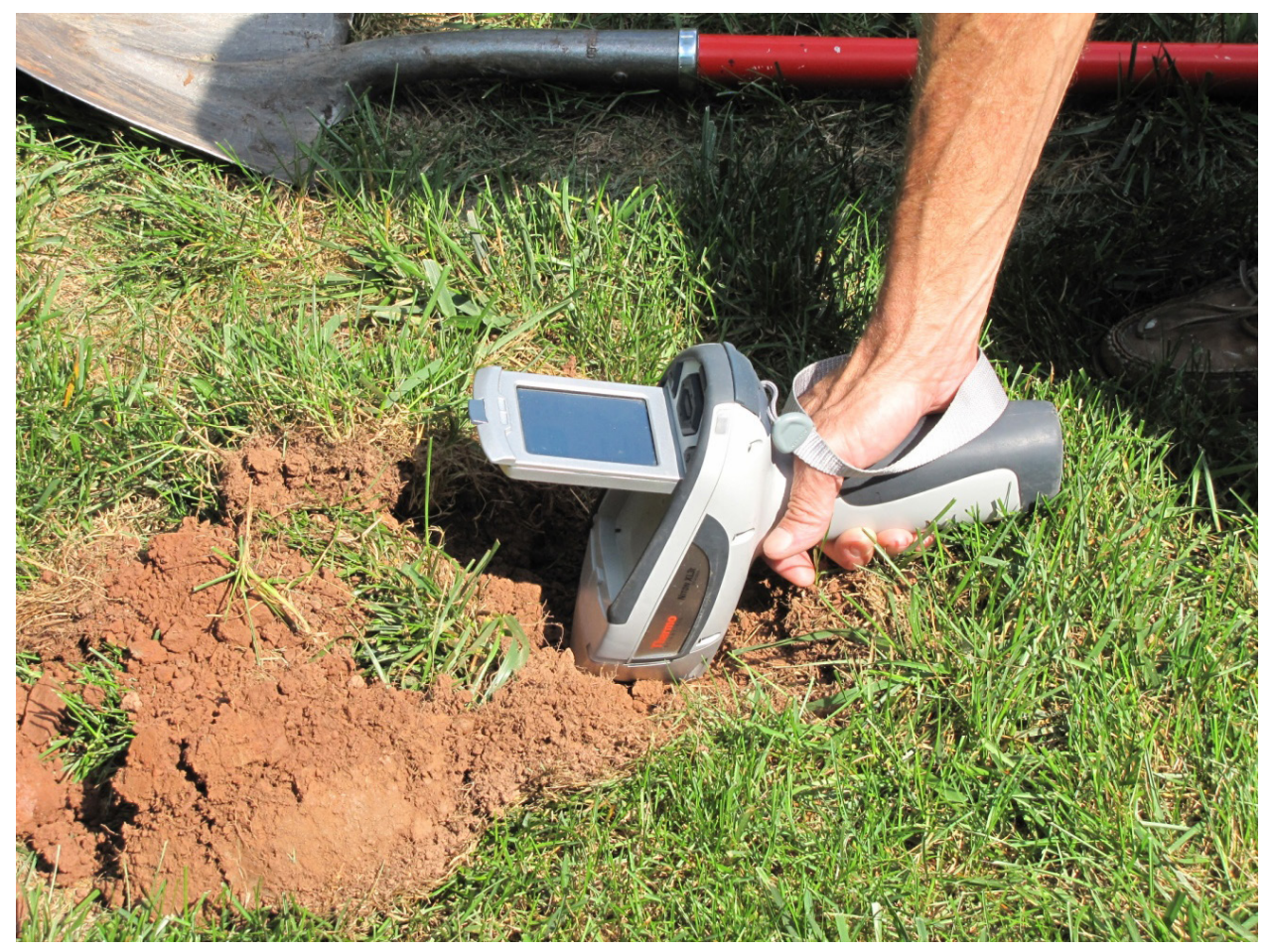

Figure 6. Soil sampling and field X-ray fluorescence (XRF) screening. (Photo by Gary Fisher, USGS.) 


\section{Analysis and Quality Control}

Soil samples were reprocessed in the laboratory using XRF methods. After soil samples were air dried, disaggregated, and sieved through a \#10 (2-millimeter) mesh, they were reprocessed with an XRF analyzer for a minimum of 3 minutes.

Soil samples were also analyzed with an ASD FR spectrometer for the presence of hydrocarbons in the soil. The spectrometer provides an analysis of spectral qualities in the near infrared beyond the spectral range of the ARCHER instrument and facilitated detailed spectral analysis in the solar-reflected spectrum. When there were spectral or field indications of the presence of hydrocarbons, water, sediment, and soil samples were collected for hydrocarbon analysis. A complete description of the field work, sampling, and quality control procedures can be found in Slonecker and Fisher (2009).

\section{Criteria for Elevated Metal Concentrations}

Heavy metals were contaminants of concern at most of the sites being evaluated. The ability of remote sensing to detect metal concentrations in soils is an important aspect of this study. All soils were analyzed in the laboratory with an ASD spectrometer for the relation between reflectance and soil metal concentrations. XRF technology was utilized to screen soil metals in the field and later, in the laboratory, to evaluate metals concentrations.

The natural level of metals in soil is called the background concentration and has been reported in the literature by comprehensive scientific studies based on regional sampling (Shacklette and Boerngen, 1984). For this study, the background concentrations were the arithmetic mean concentrations for the Eastern United States (Shacklette and Boerngen, 1984).

The risk-based concentration (RBC) of individual contaminants is a basic screening level that is also used when a potential site is initially investigated. The RBC is used to determine if potentially substantial levels of contamination are present to warrant further investigation, such as a Remedial Investigation and Feasibility Study (RI/FS). RBCs are a complex calculation of toxicity, exposure, and carcinogenic probabilities and are applied according to surrounding land use and exposure scenarios, whether residential or industrial. Table 2 lists the main metals of concern and their background concentration based on an arithmetic mean, and the residential and industrial RBCs.

The general land use surrounding the site was used to determine the appropriate RBC screening level. While this approach to the site's land use determination as residential or industrial may be debatable based on zoning classifications, the exposure scenario appeared to be primarily residential at most of the sites, and absent any clear evidence of current industrial land use, the residential RBC standard was used for reporting. The EPA regional RBCs for residential and industrial soil contaminants can be found at http://www.epa.gov/reg3hwmd/risk/human/rb-concentration_table/Generic_Tables/ (U.S. Environmental Protection Agency, 2013). 
Table 2. Listing for the background, residential-, and industrial risk-based concentrations (RBC) of selected metals.

[All measurements are listed in milligrams per kilogram. BG, background; R-RBC, residential-risk-based concentrations of metals in soil; I-RBC, industrial-risk-based concentration.] Background concentrations from Shacklette and Boerngen (1984). R-RBC and I-RBC from U.S. Environmental Protection Agency (2013).

\begin{tabular}{lcrr}
\hline \multicolumn{1}{c}{ Metal } & BG & R-RBC & I-RBC \\
\hline Antimony (Sb) & \multicolumn{3}{c}{ Arithmetic Mean } \\
Cadmium (Cd) & 0.76 & 31.0 & 410.0 \\
Chromium III (Cr) & 52.0 & 70.0 & 800.0 \\
Chromium VI (Cr) & -- & $12,000.0$ & $31,000.0$ \\
Cobalt (Co) & 9.2 & 29.0 & 56.0 \\
Lead (Pb) & 17.0 & 23.0 & 300.0 \\
Manganese (Mn) & 640.0 & 400.0 & 800.0 \\
Nickel (Ni) & 18.0 & $1,800.0$ & $23,000.0$ \\
Selenium (Se) & 0.5 & $1,600.0$ & $20,000.0$ \\
Uranium (U) & 2.7 & 390.0 & $5,100.0$ \\
Vanadium (V) & 66.0 & 230.0 & $3,100.0$ \\
Zinc (Zn) & 52.0 & 390.0 & $5,200.0$ \\
\hline
\end{tabular}

\section{Results of Analysis}

Analysis of the overhead remote sensing data and data derived from the field sampling indicated basic changes in land use and site morphology and detectable levels of metals in the soil at several sites. Hyperspectral analysis detected debris and vegetation stress at two sites: Taylor Borough Dump and Hranica Landfill. Spectral anomalies and unusual patterns of vegetation reflectance were observed at Bruin Lagoon. Conditions at the Bruin Lagoon site appear to have returned to normal (M. Hoffman, Environmental Chemist, Pennsylvania Department of Environmental Protection,written commun., June $13,2013)$. Other issues are summarized in table 3 with a discussion following.

Table 3. A summary of the results of the detection of fugitive contamination at selected Superfund hazardous waste sites in Pennsylvania.

[LU, land use; NA, not applicable; O\&M, operations and maintenance; $\mathrm{Pb}$, lead]

\begin{tabular}{|c|c|c|c|c|c|c|c|}
\hline Site name & $\begin{array}{l}\text { Field } \\
\text { visit }\end{array}$ & $\begin{array}{l}\text { Physical } \\
\text { security }\end{array}$ & LU setting & $\begin{array}{l}\text { Imagery } \\
\text { findings }\end{array}$ & $\begin{array}{c}\text { Soil Samples } \\
\text { detected above } \\
\text { RBC } \\
\text { concentrations }\end{array}$ & $\begin{array}{c}\text { O\&M } \\
\text { issues }\end{array}$ & Comments \\
\hline $\begin{array}{l}\text { Aladdin } \\
\text { Plating }\end{array}$ & Yes & No & Residential & No & No & No & -- \\
\hline $\begin{array}{l}\text { Berkley } \\
\text { Products }\end{array}$ & Yes & Yes & Residential & No & No & No & \\
\hline
\end{tabular}


Table 3. A summary of the results of the detection of fugitive contamination at selected Superfund hazardous waste sites in Pennsylvania. - Continued

[LU, land use; NA, not applicable; O\&M, operations and maintenance; $\mathrm{Pb}$, lead]

\begin{tabular}{|c|c|c|c|c|c|c|c|}
\hline Site name & $\begin{array}{l}\text { Field } \\
\text { visit }\end{array}$ & $\begin{array}{l}\text { Physical } \\
\text { security }\end{array}$ & LU setting & $\begin{array}{l}\text { Imagery } \\
\text { findings }\end{array}$ & $\begin{array}{c}\text { Soil Samples } \\
\text { detected above } \\
\text { RBC } \\
\text { concentrations }\end{array}$ & $\begin{array}{c}\text { O\&M } \\
\text { issues }\end{array}$ & Comments \\
\hline Berks Landfill & Yes & Yes & Industrial & No & Possible & No & $\begin{array}{l}\text { Possible chromium } \\
\text { issue. }\end{array}$ \\
\hline $\begin{array}{l}\text { Brodhead } \\
\text { Creek }\end{array}$ & Yes & Yes & Industrial & No & No & No & \\
\hline Bruin Lagoon & Yes & Yes & Residential & Yes & No & No & \\
\hline $\begin{array}{l}\text { Helbelka Auto } \\
\text { Salvage }\end{array}$ & No & N/A & Residential & N/A & N/A & No & \\
\hline $\begin{array}{l}\text { Hranica } \\
\text { Landfill }\end{array}$ & Yes & Yes & Industrial & Yes & No & Yes & Leachate. \\
\hline $\begin{array}{l}\text { Lackawanna } \\
\text { Refuse }\end{array}$ & Yes & Partial & Industrial & No & No & No & Damaged fence. \\
\hline $\begin{array}{l}\text { Lansdowne } \\
\text { Radiation }{ }^{1,2}\end{array}$ & No & N/A & Residential & N/A & N/A & No & \\
\hline $\begin{array}{l}\text { McAdoo } \\
\text { Blaine }\end{array}$ & Yes & No & Residential & No & No & No & \\
\hline McAdoo Kline & Yes & Yes & Industrial & No & No & No & \\
\hline $\begin{array}{l}\text { Metropolitan } \\
\text { Mirro, }\end{array}$ & No & N/A & Industrial & N/A & N/A & No & \\
\hline $\begin{array}{l}\text { Publicker } \\
\text { Industries }\end{array}$ & Yes & Yes & Industrial & No & No & Yes & $\begin{array}{l}\text { Old equipment on } \\
\text { site. }\end{array}$ \\
\hline $\begin{array}{l}\text { Taylor } \\
\text { Borough } \\
\text { Dump }\end{array}$ & Yes & Partial & Residential & Yes & $1-\mathrm{Pb}^{1}$ & Yes & Damaged fence. \\
\hline $\begin{array}{l}\text { Voortman } \\
\text { Farms }\end{array}$ & No & N/A & Residential & N/A & N/A & No & -- \\
\hline Wade ABM & Yes & No & Residential & No & No & No & $\begin{array}{l}\text { Site is now a park. } \\
\text { Most of site is } \\
\text { asphalt. }\end{array}$ \\
\hline
\end{tabular}

${ }^{1}$ At the Taylor Borough Dump, one sample exceeded the industrial risk-based concentration for $\mathrm{Pb}$.

${ }^{2}$ Site was not visited during field work.

Physical security.- It was noted that there was inadequate or no physical security at five sitesAladdin Plating, McAdoo-Blaine, Taylor Borough Dump, Lackawanna Refuse, and Wade ABM. Taylor Borough Dump was fenced but major gaps in the fencing were observed. McAdoo-Blaine is a residential area and Wade $\mathrm{ABM}$ is now a park. 
Operations and maintenance issues. - There were operations and maintenance issues at three sites: Hranica Landfill, Publicker Industries, and Taylor Borough Dump. Generally, these issues consisted of discarded equipment and general industrial debris. There were large mounds of debris at the Taylor Borough Dump site (fig. 7). Evidence of all-terrain-vehicle useage was observed at both Taylor Borough Dump and Lackawanna Refuse. A rust-colored leachate-like discharge was observed at Hranica Landfill.

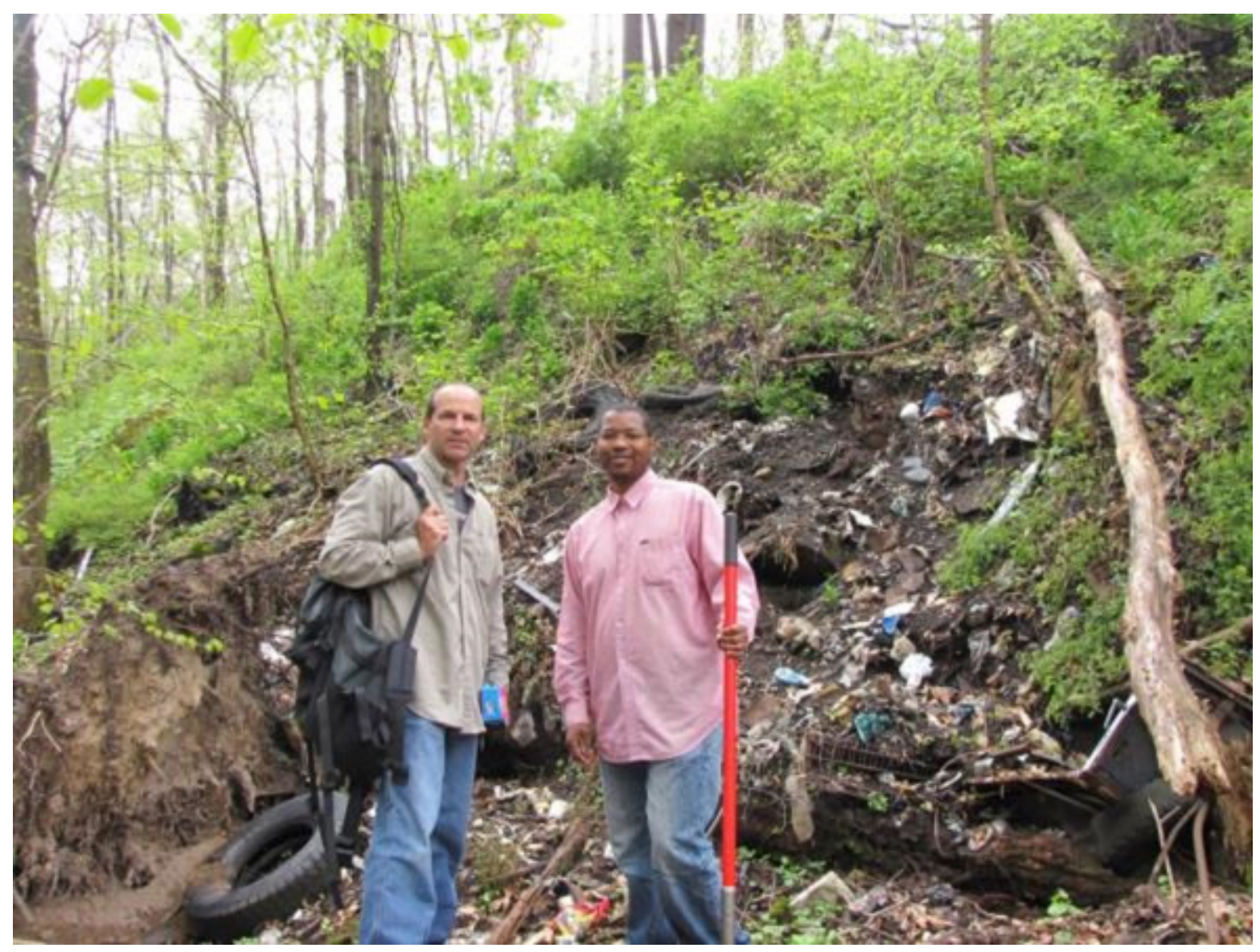

Figure 7. Office of the Inspector General evaluators standing next to a large debris pile during a site visit to Taylor Borough Dump. (Photo by Gary Fisher, USGS.)

Hyperspectral Anomalies.-Detectable hyperspectral issues were noted at Bruin Lagoon, Hranica Landfill, and Taylor Borough Dump. At Hranica Landfill and Taylor Borough Dump, substantial amounts of debris, metal equipment, and discarded material were highlighted by a hyperspectral anomaly detection algorithm (fig. 8). Vegetation stress anomalies were detected at Bruin Lagoon (fig. 9) and are discussed below. 

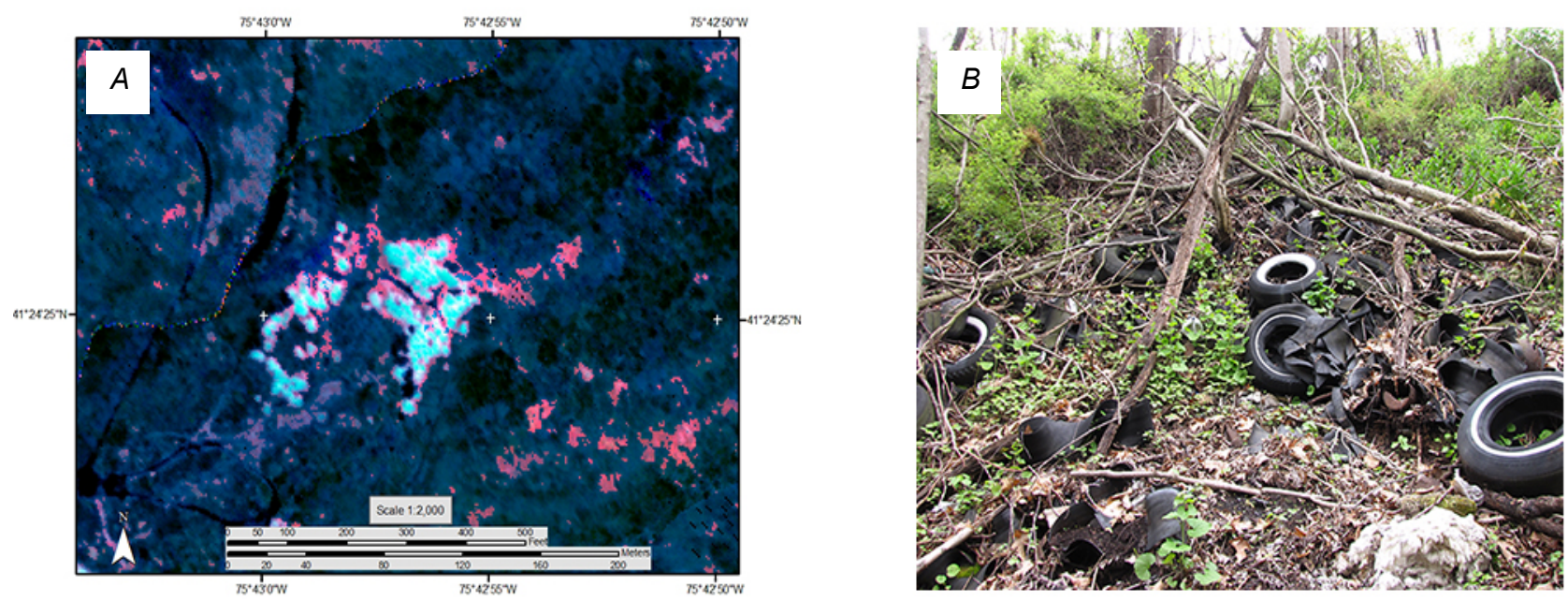

Figure 8. A, Hyperspectral image analysis of vegetation and debris stress and $B$, ground photo of large trash pile at Taylor Borough Dump. (Photo by Gary Fisher, USGS.)

Sampling Results.-The onsite soil sampling results indicated one sample exceeded the applicable residential or industrial $\mathrm{RBC}$ for $\mathrm{Pb}$ at the Taylor Borough Dump. Potentially high levels for $\mathrm{Cr}$ were detected at Berks Landfill and could pose a problem if the metal form is found to be Cr VI. However, if the form is found to be Cr III, then the levels of concentration are well within current screening level standards. Additional analysis of the soils in this area would be needed to confirm this evaluation.

Vegetation Anomalies.-Potential vegetation anomalies were observed in the cover grass at Bruin Lagoon and are shown in figure 9. These anomalies, representing patches of dead vegetation, were not visually detectable during the field visit, metal or hydrocarbon sampling results were not detected, and there were no sampling results correlating with the anomalous areas. 

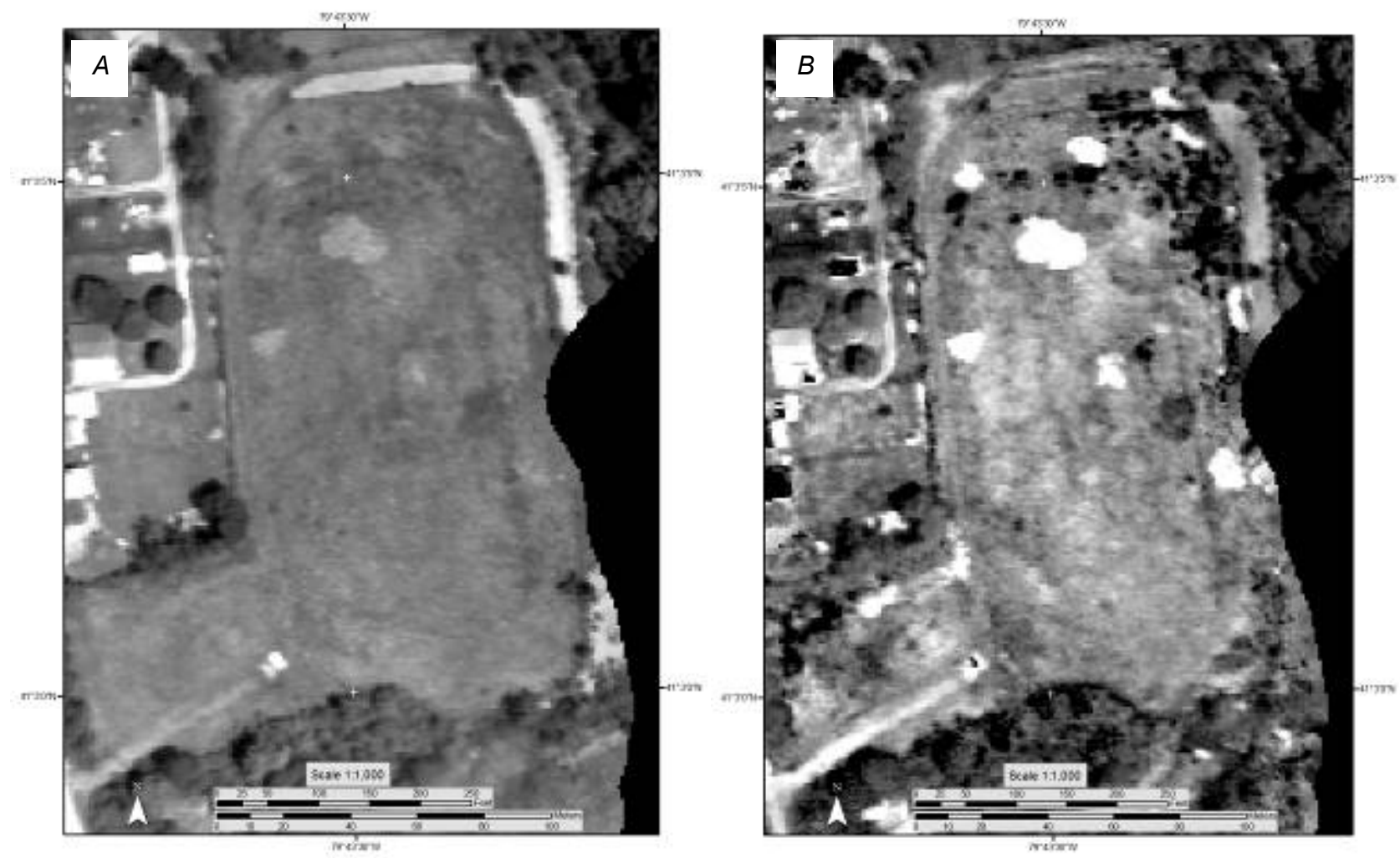

Figure 9. Bruin Lagoon: $A$, Panchromatic image on left and $B$, hyperspectral anomaly detection image on right. Vegetation stress and endmember analyses yielded the same basic patterns of dead vegetation, shown as white areas in image $B$.

A hyperspectral reflight in November 2012 showed only traces of the dead vegetation anomalies. One of the possible explanations of this event is that gases may be moving upward from the original lagoon. Spectral analysis of these anomalous areas shows a pattern of vegetation stress manifested in the spectral signatures that is consistent with the published works of Noomen and others $(2003,2008)$, who investigated the effect of leaking natural gas on vegetation above pipelines. The continuum-removed spectra in figure 10 illustrate this natural gas effect on vegetation.

Figure 10 contains a continuum-removed plot of normal vegetation (white) and the vegetation anomaly (red), showing loss of photosynthetic band depth at about $680 \mathrm{~nm}$ and a general "red-edge" shift of 8-12 nm, consistent with previously published results on natural gas stress. Although interesting, this finding is not conclusive because other factors could cause this type of spectral signature shift. From a technical perspective, further analysis is needed. An inspection of the site in June 2013 by Pennsylvania State officials indicated that the Bruin Lagoon site had revegetated normally and that no anomalies were present (M. Hoffman, Environmental Chemist, Pennsylvania Department of Environmental Protection, written commun., June 13, 2013). 


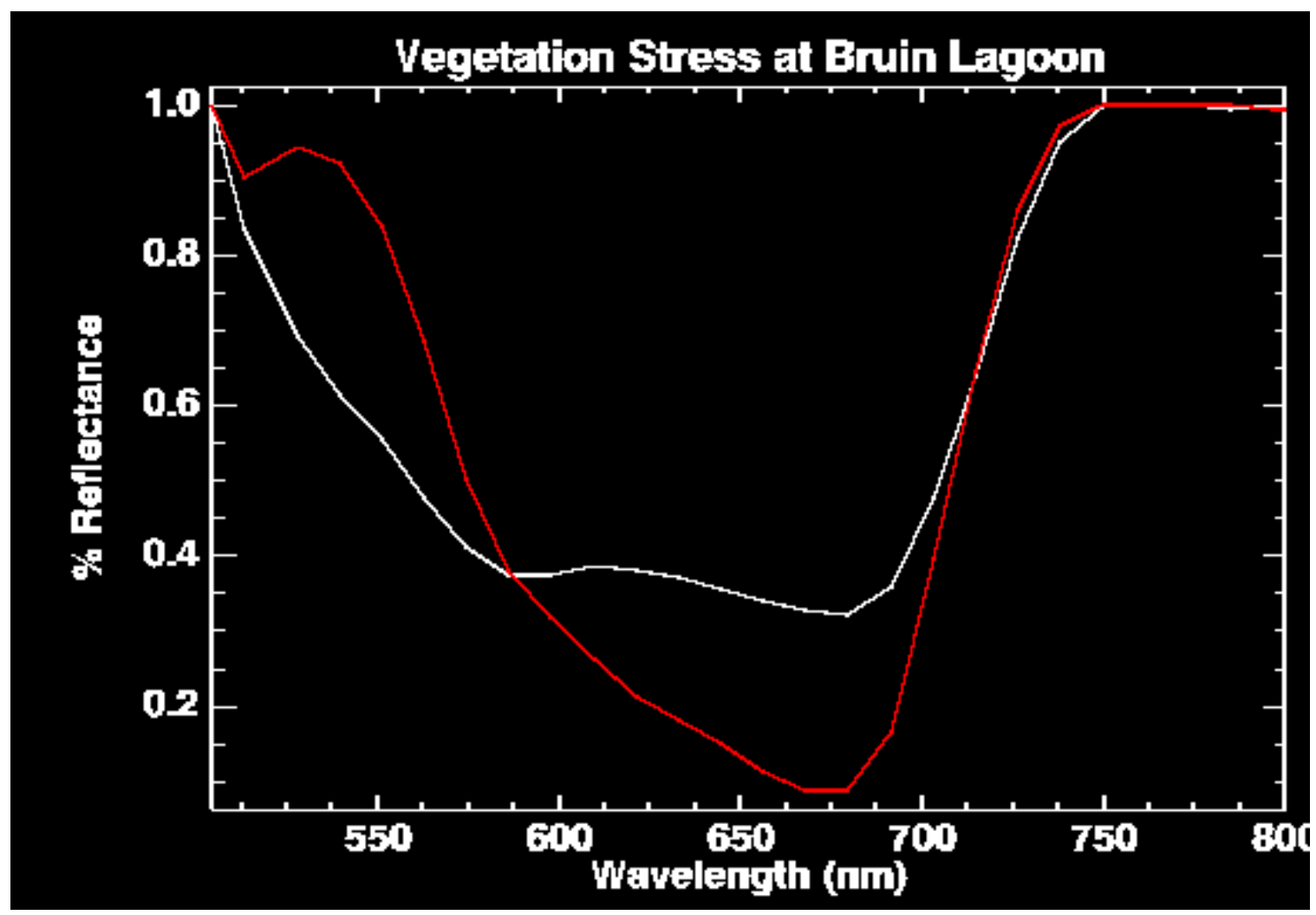

Figure 10. Continuum-removed plot of normal vegetation (white) and a vegetation anomaly (red), showing loss of photosynthetic band depth around 680 nanometers $(\mathrm{nm})$ and a general "red-edge" shift of 8-12 nm, consistent with previously published results on natural gas stress (Noomen and others, 2003, 2008).

\section{Summary and Conclusions}

Important findings of this study include the following:

- Remote sensing did not identify potential contamination concerns at nine sites, and these findings were subsequently confirmed with field visits.

- Soil screening and sampling results indicated one sample exceeded the applicable residential- or industrial-risk-based concentration for $\mathrm{Pb}$ at the Taylor Borough Dump; $\mathrm{Pb}$ concentrations at approximately 1,500 milligrams per kilogram were detected and confirmed. Physical security and operations and maintenance issues were noted at several sites.

- Hyperspectral analysis identified potential contamination concerns at Hranica Landfill and Taylor Borough Dump, which were found to correlate with operations and maintenance issues and site conditions during field inspections.

- Hyperspectral analysis revealed an unusual pattern of vegetation stress at Bruin Lagoon, and subsequent hyperspectral overflights showed a continued pattern of unusual vegetation reflectance at this site. Recent visits by Pennsylvania officials indicate that onsite vegetation appears to be normal. Both from an operational monitoring and remote sensing research perspective, additional monitoring at this site is potentially important. 
This research effort, and the work that preceded this study, utilized a suite of remote sensing tools, including conventional imaging, imaging spectroscopy, laboratory spectroscopy, and XRF, to evaluate the potential of this technology for postclosure status of deleted SF sites in EPA Region 3. Combined standoff and in situ approaches, such as utilizing laboratory spectrometers, were used to maximize the total range of the solar-reflected spectrum and to keep costs reasonable. The goal of this study was to simulate, as much as possible, the full range of the solar-reflected electromagnetic spectrum (from 400 to 2,500 nm). This technology, like many research technologies, is moving into an applications environment and monitoring costs are decreasing. Ideally, this research and the monitoring applications that follow will one day be conducted using a full-range overhead hyperspectral sensor, such as the Airborne Visible/Infrared Imaging Spectrometer (AVIRIS) or the Hyperspectral MAPper (HyMAP) (HyVista Corporation, Castle Hill, Australia), which permits the complete utilization of a full solar-reflected range imaging sensor.

Several scientific lessons learned can be identified from this research, along with potential research opportunities.

- Operations and maintenance at several sites was an issue and hyperspectral anomaly detection has been shown to be effective in identifying discarded materials in this scenario. Trash, debris, and remnants of operational activities were found and often unsecured from public access.

- Vegetation stress is one of the most likely observables in the monitoring of hazardous waste sites. However, the vegetation cover and mix of species is likely to be different, depending on the nature of the sites' conditions. Similarly, the timing of hyperspectral imagery is different, depending on seasonal considerations. Sites with low-level cover vegetation are best imaged in the summer, and sites with extensive tree cover may have to be imaged in both leaf-on and leaf-off conditions.

- Grasses and low-level cover and forest stress are likely to show reflectance differences in specific vegetation indices, such as water content and light use efficiency, while grasses and low-level cover vegetation are more than likely sensitive to nitrogen content indices.

- Overall, this technology has now been tested on 21 deleted sites and has uncovered potential issues at five of those sites; these sites were all in EPA Region 3. Some type of extra-regional or national sample could be beneficial at the program level. Also, prescreening of sites for potential field work with existing overhead imagery could be cost-effective and reduce the resource expenditure for the use of a hyperspectral sensor. Many of the sites with operations and maintenance issues, might have been easily identified on freely available imagery and could have been used to rank sites for potential research issues.

This research provides only a limited range of potential hazardous waste applications. Better selection of site contamination profiles and use of better overhead sensors, which are becoming more widely available, would have more potential for positive monitoring results. While the technical approach utilized in these sites was designed to permit a practical utilization of technological capabilities over a maximum number of sites, the eventual test will come with use of a full-range (400-2,500-nm) aircraft or satellite sensor and with little or no field work, only verification. This is the ultimate monitoring scenario that would be most helpful to the EPA. New sensors, including those mounted on an unmanned aerial system could now permit a practical application and could be considered in future applications. 


\section{References Cited}

Allen, C.S., and Krekeler, M.P.S., 2010, Reflectance spectra of crude oils and refined petroleum products on a variety of common substrates, in Gilbreath, C.G., and Hawley, G.T., eds., Active and passive signatures: Proceedings of the International Society for Optics and Photonics, v. 7687, [unpaginated].

Baker, S.J., 1984, Historical aerial photographic analysis, Ringwood mines and landfills: U.S. Environmental Protection Agency Report TS-PIC-83044, 2 vols.

Butler, L.R.P., and Laqua, K., 1995, Nomenclature, symbols, units and their usage in spectrochemical analysis, in Part IX; Instrumentation for the spectral dispersion and isolation of optical radiation: International Union of Pure and Applied Chemistry Recommendations 1995, 18 p.

Chang, S.H., and Collins, William, 1983, Confirmation of the airborne biogeophysical mineral exploration technique using laboratory methods: Economic Geology, v. 78, no. 4, p. 723-736.

Choe, E., van der Meer, F., Ruitbeek, F., van der Werff, H., Smeth, B. and Kim, K-W, 2008, Mapping of heavy metal pollution in stream sediments using combined geochemistry, field spectroscopy, and hyperspectral remote sensing-A case study of the Rodalquilar mining area, SE Spain: Remote Sensing of Environment, v. 11, no. 7, p. 3222-3233.

Civil Air Patrol , 2009, ARCHER - CAP advanced technologies: Civil Air Patrol presentation, 21 p, accessed April 14, 2011, at http://www.dnr.mo.gov/env/hwp/hsi/cap-archer.pdf.

Clark, R.N., 1999, Spectroscopy of rocks and minerals, and principles of spectroscopy, chap. 1 of Manual of remote sensing, v. 3 of Rencz, A.N., ed., Remote Sensing for the Earth Sciences: New York, John Wiley and Sons, p. 3-58.

Clark, R.N., Curchin, J.M, Hoeffen, T.M., and Swayze, G.A., 2009, Reflectance spectroscopy of organic compounds-1. Alkanes: Journal of Geophysical Research, v. 114, no. E03001, p. 19.

Cloutis, E.A., 1989, Spectral reflectance properties of hydrocarbons; Remote-sensing implications: Science, v. 245, no. 4914, p. 165-168.

Colwell, R.N., 1956, Determining the prevalence of certain cereal crop diseases by means of aerial photography: Hilgardia, v. 26, p. 223-286.

Farrand, W.H., and Harsanyi, J.C., 1997, Mapping the distribution of mine tailings in the Coeur d'Alene River Valley, Idaho, through the use of a constrained energy minimization technique: Remote Sensing of Environment, v. 59, no. 1, p. 64-76.

Ferrier, G., 1999, Application of imaging spectrometer data in identifying environmental pollution caused by mining at Rodaquilar, Spain: Remote Sensing of Environment, v. 68, no. 2, p. 125-137.

Gamon, J.A., Peñuelas, J., and Field, C.B., 1992, A narrow-waveband spectral index that tracks diurnal changes in photosynthetic efficiency: Remote Sensing of Environment, v. 41, p. 35-44.

Gamon, J.A., Serrano, L., and Surfus, J.S., 1997, The photochemical reflectance index; An optical indicator of photosynthetic radiation use efficiency across species, functional types and nutrient levels: Oecologia, v. 112, p. 492-501.

Goetz, A.F.H., Vane, Gregg, Solomon, J.E., and Rock, B.N., 1985, Imaging spectroscopy for earth remote sensing: Science, v. 228, no. 4704, p. 1147-1153. 
Green, R.O., Eastwood, M.L., Sarture, C.M., Chrien, T.G., Aronsson, M., Chippendale, B.J., Faust, J.A., Pavri, B.E., Chovit, C.J., Solis, M., Olah, M.R., and Williams, O., 1998, Imaging spectroscopy and the airborne visible/infrared imaging spectrometer (AVIRIS): Remote Sensing of Environment, v. 65 , no. 3, p. 227-248.

Horler, D.N.H., Barber, J., and Barringer, A.R., 1980, Effects of heavy metals on the absorbance and reflectance spectra of plants: International Journal of Remote Sensing, v. 1, p. 121-136.

Kemper, T., and Sommer, S., 2002, Estimate of heavy metal contamination in soils after a mining accident using reflectance spectroscopy: Environmental Science \& Technology, v. 36, no. 12, p. $2742-2747$.

King, T.V.V., and Clark, R.N., 1989, Reflectance spectroscopy (0.2 to $20 \mu \mathrm{m})$ as an analytical method for the detection of organics, in Proceedings of the First International Symposium; Field Screening Methods for Hazardous Waste Site Investigations: U.S. Environmental Protection Agency, p. $485-488$.

Milton, N.M., Ager, C.M., and Eiswert, B.A., and Power, M.S., 1989, Arsenic- and selenium-induced changes in spectral reflectance and morphology of soybean plants: Remote Sensing of Environment, v. 30, no. 3, p. 263-269.

Montero S.I.C., Brimhall, G.H., Alpers, C.N., and Swayze, G.A., 2005, Characterization of waste rock associated with acid drainage at the Penn Mine, California, by ground-based visible to short-wave infrared reflectance spectroscopy assisted by digital mapping: Chemical Geology, v. 215, no. 1, p. 453-472.

National Aeronautics and Space Adminsitration, 2007, AVIRIS concept, http://aviris.jpl.nasa.gov/html/aviris.concept.html.

National Aeronautics and Space Administration, 2010, AVIRIS Moffett Field Image Cube, http://aviris.jpl.nasa.gov/html/aviris.cube.html.

Noomen, M.F., Skidmore, A.K., and Van der Meer, F.D., 2003, Detecting the influence of gas seepage on vegetation, using hyperspectral remote sensing, in Proceedings of the Third EARSeL Workshop on Imaging Spectroscopy, Herrsching, Germany, May 13-16, 2003: Herrsching, Germany, p. 252-56.

Noomen, M.F., Smith, K.L., Colls, J.J., Steven, M.D., Skidmore, A.K., and Van Der Meer, F.D., 2008, Hyperspectral indices for detecting changes in canopy reflectance as a result of underground natural gas leakage: International Journal of Remote Sensing, v. 29, no. 20, p. 5987-6008.

Rood, J.W., Jr., 1879, Modern chromatics with applications to art and industry: New York, D. Appleton \& Company.

Schull, C.A., 1929, A spectrophotometric study of reflection of light from leaf surfaces: The Botanical Gazette, v. 87, p. 583-607.

Shacklette, H.T., and Boerngen, J.G., 1984, Element concentrations in soils and other surficial materials of the conterminous United States: U.S. Geological Survey Professional Paper 1270, 105 p., http://pubs.usgs.gov/pp/1270/pdf/PP1270_508.pdf.

Slonecker, E.T., and Fisher, G.B. 2009, Research implementation and quality assurance project plan; An evaluation of hyperspectral remote sensing technologies for the detection of fugitive contamination at selected Superfund hazardous waste sites: U.S. Geological Survey Open-File Report 2009-1048, 18 p., http://pubs.usgs.gov/of/2009/1048/. 
Slonecker, E.T., Fisher, G.B., Aiello, D.P., and Haack, B.N., 2010, Visible and infrared remote sensing of hazardous waste; A review: Remote Sensing, v. 2, no. 11, p. 2474-2508, http://www.mdpi.com/2072-4292/2/11/2474.

Slonecker, E.T., and Fisher, G.B., 2011, An evaluation of traditional and emerging remote sensing technologies for the detection of fugitive contamination at selected Superfund hazardous waste sites: U.S. Geological Survey Open-File Report 2011-1050, 16 p., http://pubs.usgs.gov/of/2011/1050/.

Stevenson, B., O'Connor, R., Kendall, W., Stocker, A., Schaff, W., Alexa, D. , Salvador, J., Eismann, M., Barnard, K., and Kershenstein, J., 2005, Design and performance of the Civil Air Patrol ARCHER hyperspectral processing system, in Defense and Security: International Society for Optics and Photonics, p. 731-742. (Also available at http://dx.doi.org/10.1117/12.604471.)

Thenkabail, P.S., Smith, R.B., and De Pauw, E., 2000, Hyperspectral vegetation indices and their relationships with agricultural crop characteristics: Remote Sensing of Environment, v. 71, no. 2, p. $158-182$.

Thermo Scientific, 2013, How XRF works, accessed December 11, 2013, at http://www.niton.com/en/portable-xrf-technology/how-xrf-works.

U.S. Environmental Protection Agency, 2010, EPA should improve oversight of long-term monitoring at Bruin Lagoon Superfund Site in Pennsylvania: U.S. Environmental Protection Agency, Office of Inspector General, Evaluation Report No. 10-P-0217, September 8, 2010.

U.S. Environmental Protection Agency, 2007, Limited investigation led to missed contamination at Ringwood Superfund Site: U.S. Environmental Protection Agency, Office of Inspector General, Evaluation Report No. 2007-P-00039, September 25, 2007.

U.S. Environmental Protection Agency, Region 3, 2013, Mid-Atlantic Risk Assessment, generic tables, risk-based concentration tables, http://www.epa.gov/reg3hwmd/risk/human/rbconcentration_table/Generic_Tables/index.htm.

Vane, G., and Goetz, A.F.H., 1988, Terrestrial imaging spectroscopy: Remote Sensing of Environment, v. 24 , no. 1 , p. 1-29.

Willstatter, R., and Stoll, A., 1913, Untersuchungen uber chlorophyll; Method und ergbnisse: Berlin, J. Springer, $435 \mathrm{p}$.

Willstatter, R., and Stoll, A., 1918, Untersuchungen uber die assimilation der kohlensaure: Berlin, J. Springer, $448 \mathrm{p}$.

Wu, Y., Chen, J., Ji, J., Gong, P., Liao, Q., Tian, Q., and Ma, H., 2007, A mechanism study of reflectance spectroscopy for investigating heavy metals in soils: Soil Science Society of America Journal, v. 71, no. 3, p. 918-926.

Zinnert, J.C., Via, S.M., and Young, D.R., 2012, Distinguishing natural from anthropogenic stress in plants; Physiology, fluorescence and hyperspectral reflectance: SpringerLink, v. 366, nos. 1-2, p. 133-141. 


\section{Glossary}

Anomaly Detection

electromagnetic spectrum

endmember

hyperspectral imagery

hyperspectral imagery analysis

operations and maintenance
Anomaly Detection (AD), in general terms, refers to detecting patterns in a given dataset that do not conform to an established normal behavior. It is also known statistically as "outlier detection" (Wikipedia). In spectral analysis, it is the identification of pixels that statistically deviate from the spectral profiles of surrounding pixels. In practice, it is used to identify situations, such as metal pieces of a downed aircraft or the disposal of metal wastes in a vegetation environment.

The electromagnetic spectrum (EM) is the range of all possible frequencies of electromagnetic radiation (EMR). The "electromagnetic spectrum" of an object has a different meaning, and is instead the characteristic distribution of EMR remitted or absorbed by that particular object. The electromagnetic spectrum extends from below the low frequencies used for modern radio communication to gamma radiation at the short-wavelength (highfrequency) end, thereby covering wavelengths from thousands of kilometers down to a fraction of the size of an atom. This study utilized the "solar-reflected" portion of the EM that included visible light and the near infrared wavelengths of approximately 400 to 2,500 nanometers.

In mineralogy, an endmember is a mineral that is at the extreme end of a mineral series in terms of purity. Minerals often can be described as solid solutions with varying compositions of some chemical elements, rather than as substances with an exact chemical formula. In imaging spectroscopy, endmembers are the purest pixels in hyperspectral imagery (HSI), and represent the key spectral profiles that affect other pixels in the dataset.

A form of remote sensing in which imagery is collected in numerous (usually 50-200), contiguous, spectrally narrow, coregistered bands of imagery that can be analyzed with spectroscopic techniques.

Hyperspectral imagery analysis, also known as "imaging spectroscopy," is a remote sensing technique that collects emitted or reflected energy in discrete, narrow wavelengths that are processed and analyzed with spectroscopic laboratory techniques as opposed to standard image analysis.

A series of actions and monitoring measures that are designed to maintain the remedy at a hazardous waste site to ensure that the remedy remains protective of human health and the environment. 
reflectance

spectral analysis

spectral analyst

spectrometer

vegetation stress

X-ray fluorescence
The measure of electromagnetic energy reflected from a surface relative to a standard, highly reflective surface, usually spectralon.

A generic name for a body of analytical techniques based on measuring the reflected or emitted energy of a material.

A specific set of processing steps that are utilized for general spectral analysis by the Environment for Visualing Imagery (ENVI) software program.

A spectrometer (spectrophotometer, spectrograph, or spectroscope) is an instrument used to measure properties of light over a specific portion of the electromagnetic spectrum, typically used in spectroscopic analysis to identify materials (Butler and Laqua, 1995).

In imaging spectroscopy, a mathematical measure, or index value that is computed from band-specific reflectance values and relates to the physiological functions of a plant, indicating its relative health. There are many vegetation indices (VIs) that measure specific functions and biochemical concentrations. Widely accepted vegetation indices include the Normalized Difference Vegetation Index (NDVI) and the photochemical reflectance index (PRI).

The emission of characteristic "secondary" (or fluorescent) X-rays from a material that has been excited by bombarding with highenergy X-rays or gamma rays. The phenomenon is widely used for elemental analysis and chemical analysis, particularly in the investigation of metals, glass, ceramics, and building materials, and for research in geochemistry, forensic science, and archaeology. 
ISSN 2331-1258

http://dx.doi.org/10.3133/ofr20141081 